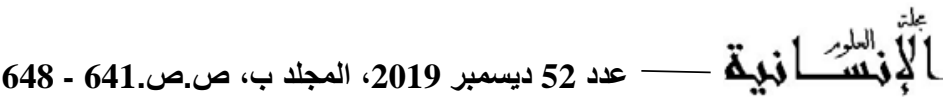

\title{
إشكالات الاستفادة من مراسيم العفو في حالة تعدد العقوبات
}

Problems benefiting from the amnesty decrees in case of multiple penalties

تاريخ الاستلام : 2019/07/16 ؛ تاريخ القبول : 2019/09/19

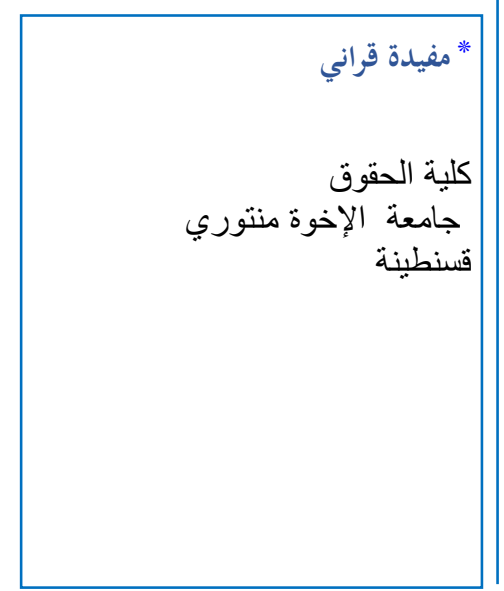

\section{Abstract}

The présidentiel pardon decrees issued constantly and annually, on the occasion of national and religious holidays,exclude every year a new category of crimes whose perpetrators are deprived of pardon.

This exclusion that presents difficulties when calculating the reduction of sentences granted totally or partially or partially, in case of penalties where there is a plurality.

The fact that one of these penalties is excluded from benefiting of the right of pardon, is integrated with other penalties, means that the exclusion includes the rest of sentences, if they were lifted simultaneously to the penitentiary (penal) institution.

Keywords: penalty; pardon; Plurality ; Confusion ; Exclusion .

\section{Résumé}

Les décrets des grâces présidentielles publies d'une manière constante et annuelle a l'occasion des fêtes nationales et religieuses excluent, chaque année, une nouvelle catégorie de crimes, dont les auteurs sont privés de bénéficier de la grâce

Cette exclusion qui présente des difficultés au niveau du calcul des réductions des peines accordées en partie ou bien en totalité, dans le cas de confusion des peines lors d' une présence d'une pluralité.

Le fait que l'une de ces pénalités est exclue du droit de bénéfice de la grâce, soit intégrée avec d'autres, donc cette exclusion inclut le reste des pénalités, si elles étaient portées simultanément devant l' institution pénitentiaire.

Mots clés: peine; grâce ; pliralité; Confusion; Exclusion.

* Corresponding author, e-mail: benkerourmouf@gmail.com 


\section{| - مقدمة}

يعتبر العفو من ضمن الأنظمة الجنائية التي عرفتها أغلب التشريعات القانونية وهو

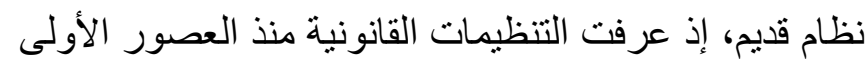

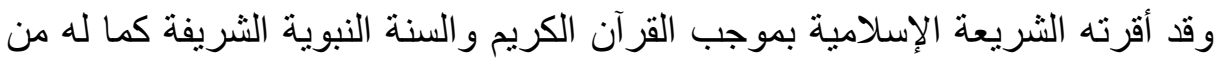

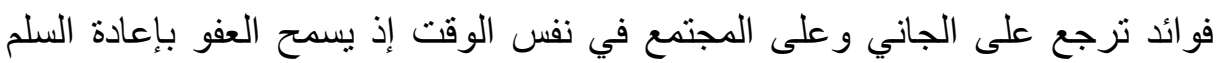
الأمان إلى المجتمع والتغاضي عن آغلاط وتجاوز التئ فات وقعت في حقبات زمنية عسيرة

وبالتالي إسدال ستار النسيان عليها وترك المجال ألكثر للتصالح والتهان والتسامح و والرحمة.

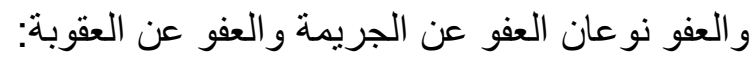

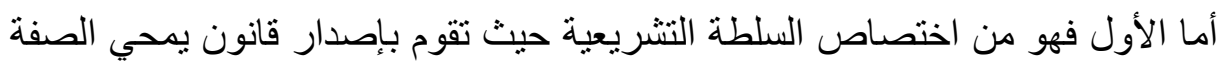

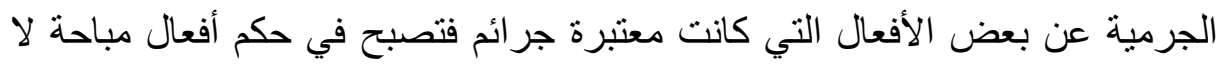

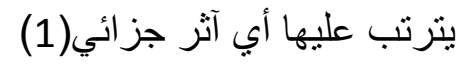

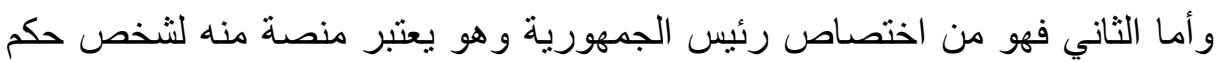

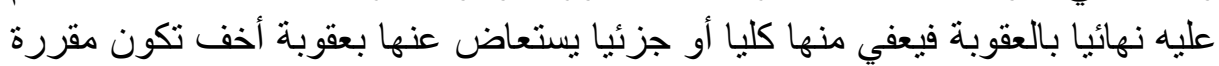
قانونام(2).

وبطبق العفو بصفة فردية أو جماعية باختلاف نوعه على المحكوم عليهم داخل

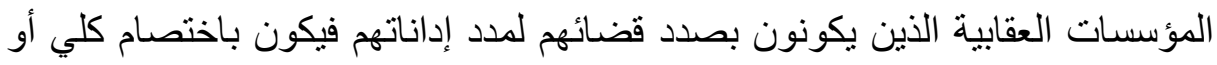

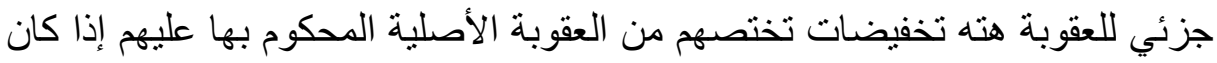

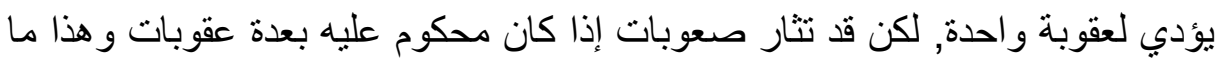

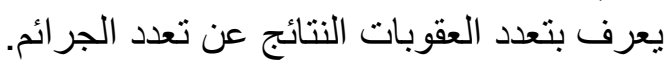

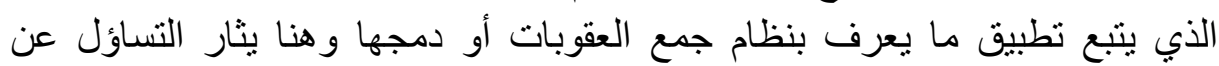
الصعوبات التي تواجه تطبيق العفو في حالة دمج أو جمع العقوبات وكئ وكيفية احتساب التخفيضات في هته الحالةّ؟ و وعليه يتمحور موضوع هذه الدراسة حول معرفة وإيراز إنهات الفرق بين نظامي دمج وجمع العقوبات و الإشكاليات التي يثر ها نطبيق مر اسيم العفو في حالة تعدد العقوبات.

\section{أولا: تعدد العقوبات:}

يعتبر تعدد العقوبات كأثر ناتج عن تعدد الجرائم المرتكبة من طرف شخص التص واحد

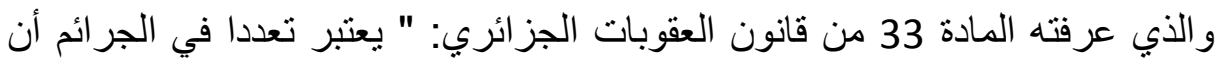

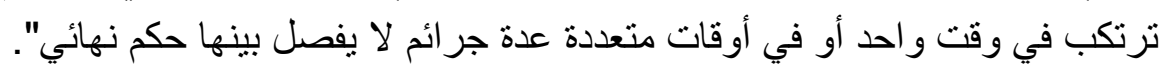

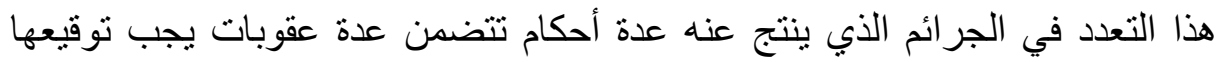
على شخص و احد. فقد توقع على الجاني عدة عقوبات بقر عدد جرائمه وهو ما يعرف بنظام الجمع

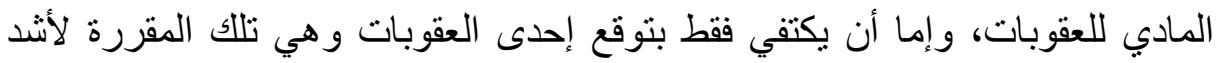

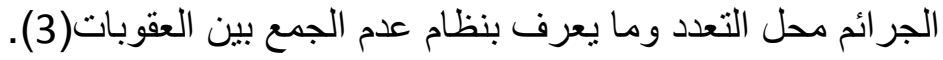

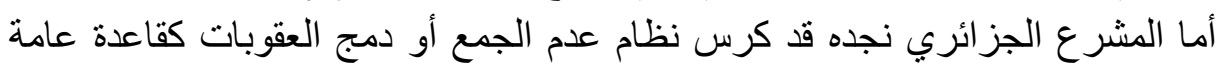

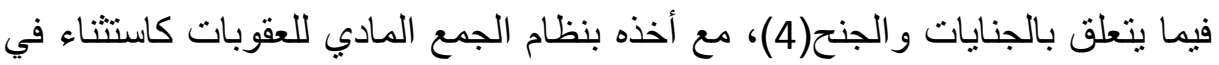

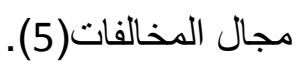


1- نظام عدم الجمع بين العقوبات أو دمج العقوبات:

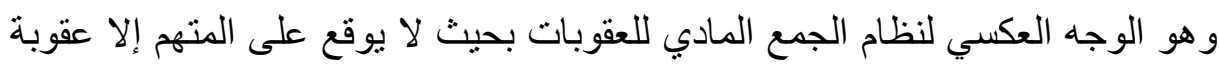

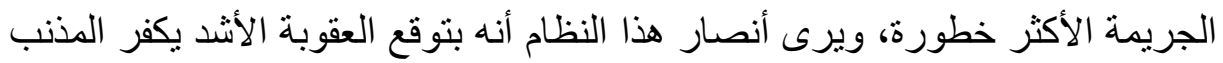

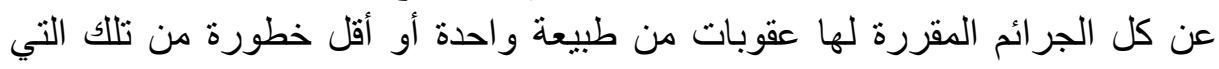
وقعت عقوبتها، وأن العقوبة الواحدة تكفي للتكفير عن الجرائم المرتكبة، أما باقي أتي العقوبات فهي عديمة الجدوى.

1- أـ التعدد الناتج عن وحدة المتابعة:

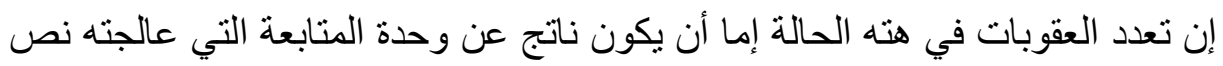

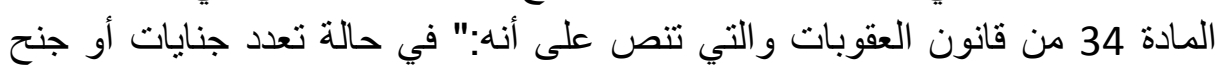

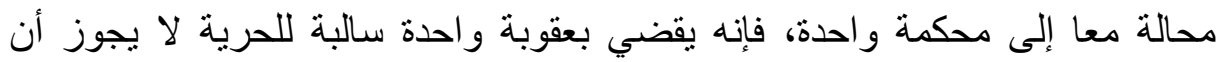

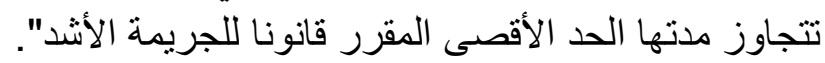

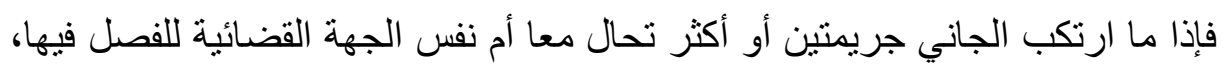

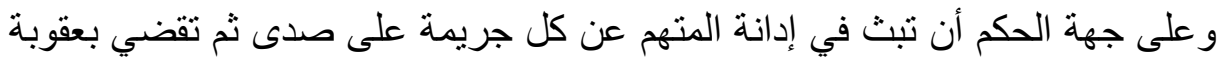

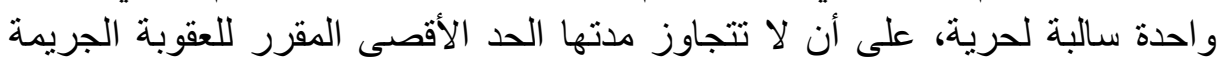

الأشد(6). (6)

وقد كرس القضاء الجزائري هذه القاعدة بموجب قرار قضائي صادر عن المحكمة

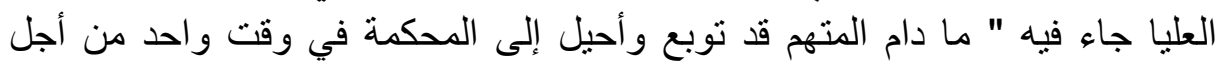

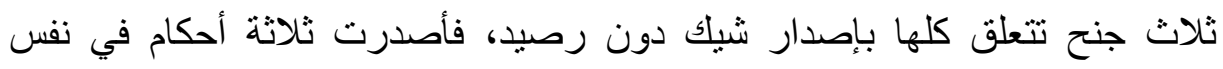

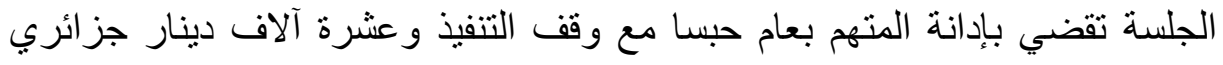

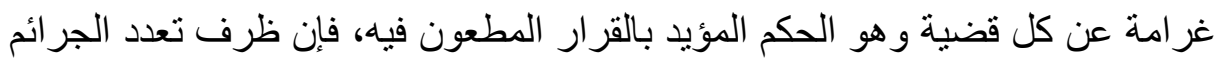

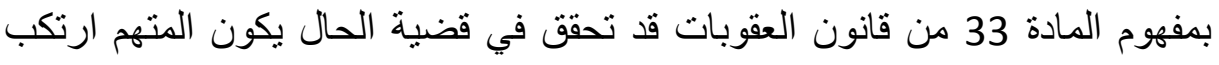
ثلاثة جنح تتعلق باصدار شيك بدون رصيد في أوقات متعددة لا يفصل فئون بينها حكم

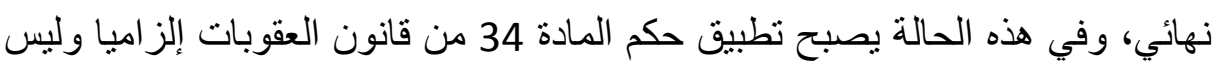
جوازيا(7). 1 - ب التعدد الناتج عن تعدد المتابعات:

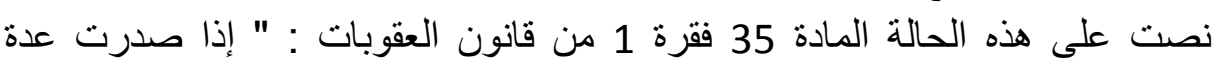

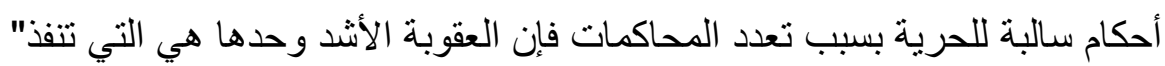

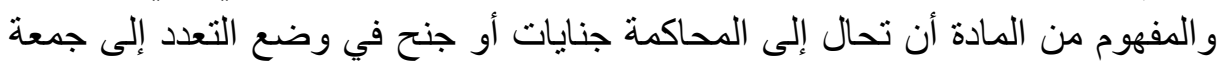

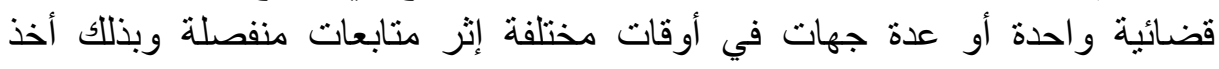

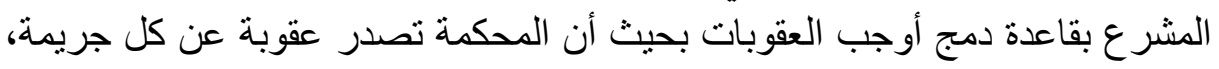
وتتفيذ منها العقوبة الأشد.

وعلى سبيل المثال أو ارتكب شخص ثند ثناثن سرقات، وكان محل متابعات منفصلة فتصدر هذه ثلاثة أحكام قضائية مختلفة فيعاقب بموجب الدي الحكم الأول بسنتين حبسا نافذا

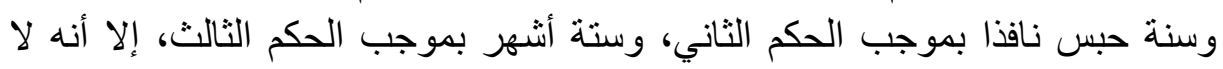

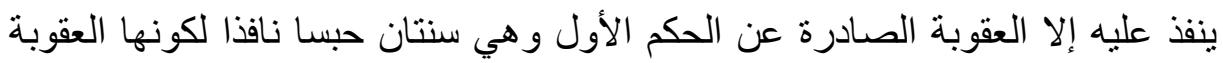

الأشد(8). 
وقد استقر قضاء المحكمة العليا على أن الأمر في هذه الحالة يتعلق بتنفيذ العقوبات

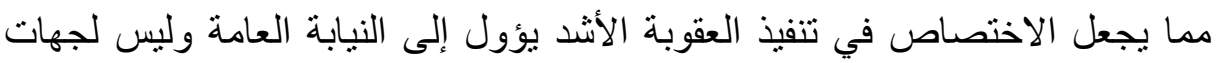

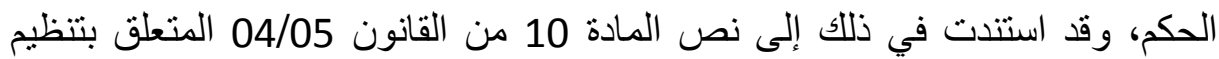

السجون و إعادة الإدماج الاجتماعي للمحبوسين(9). 2- نظام جمع العقوبات:

يقوم هذا النظام على توقيع العقوبات مجتمعة عن كل الجرائم المرتكبة من طبق

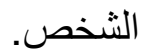
حيث أن كل جريمة لها عقوبتها مهما كانت الأفعال والجرائم ولقد كرس المشرع

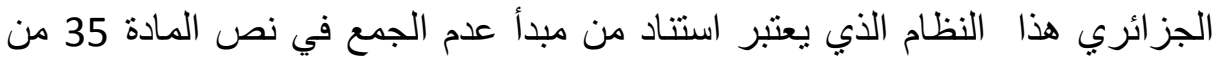
قانون العقوبات الجزائري.

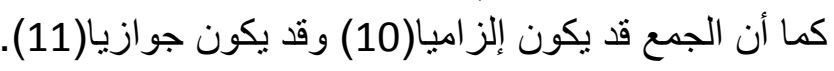
3- أ- الجمع الإلز امى للعقوبات:

نصت عليه المادة 38 من قانون العقوبات لإنوات ويكون الجمع إلزاميا في مواد المخالفات

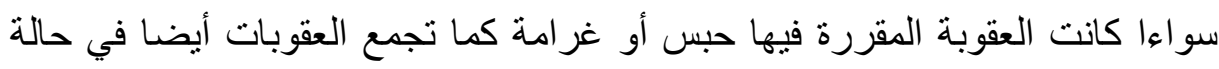

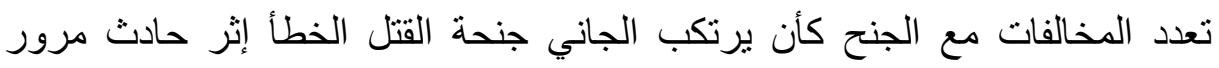

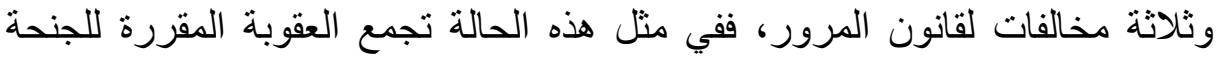

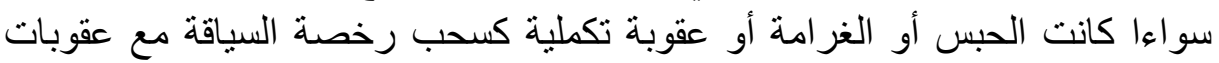

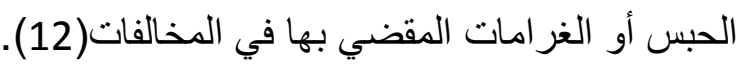

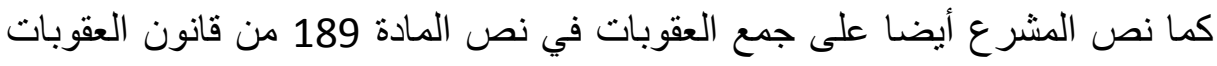

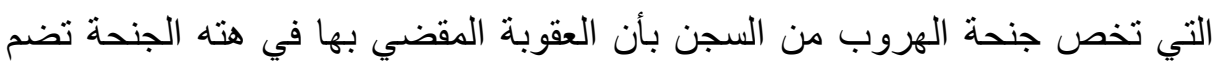

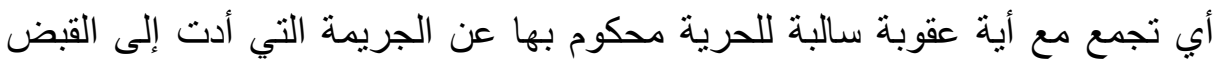
عليه وحبسه، و هذا يشكل استثناء من نص المادة 35 قانون عقوبة البهات.

\section{2-ب الجمع الجوازي للعقوبات:}

نصت على ذلك المادة 35 فقرة 2 من قانون العقوبات، أنه إذا كانت العقوبة المحكوم

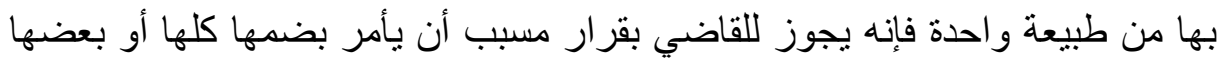

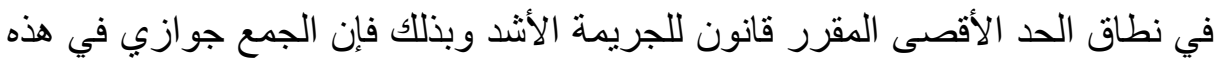

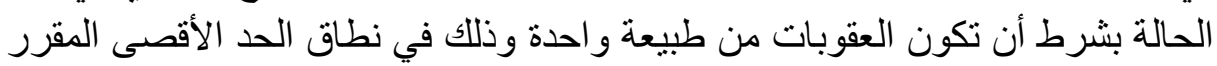

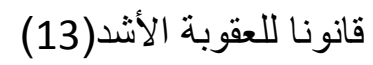

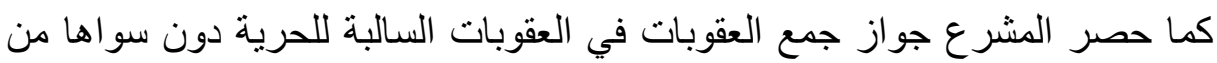

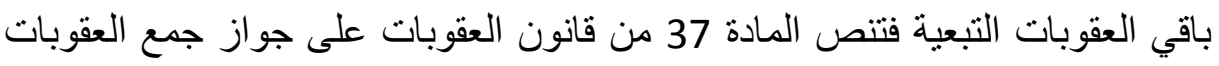

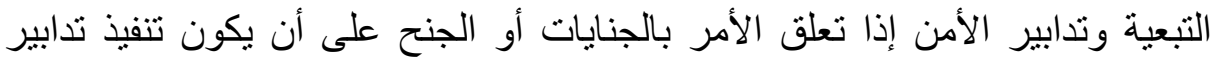

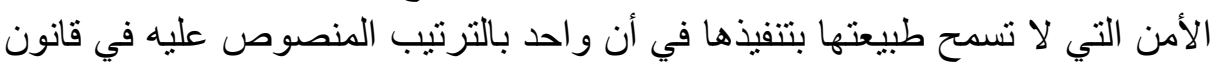

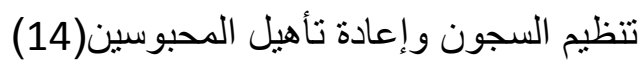
أما المادة 36 من قانون العقوبات فقد نصات تاهي على جمع العقوبات المالية مالم ينص القاضي على خلاف ذلك. 
ثانيا: الإشكالات التى تثير ها تطبيق مراسم العفو في حالة تعدد العقوبات:

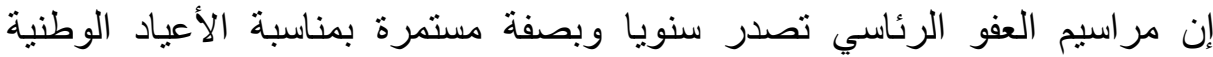
و الدينية بحيث يعفي كل مرسوم قر ابا 6000 محكوم عليهم من مختلف فئاتهم.

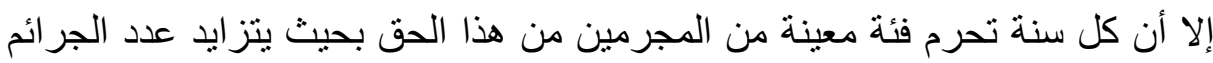
المستثناة من حق العفو التي يتم النص عليها صر احة في المرسوم.

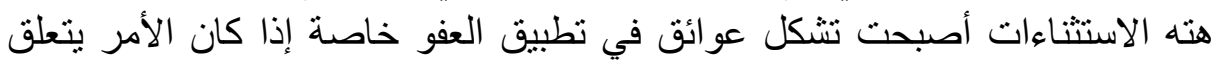

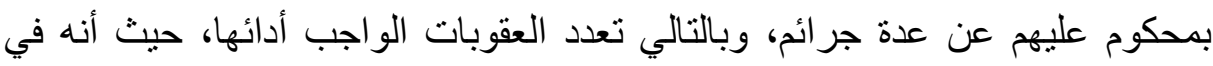

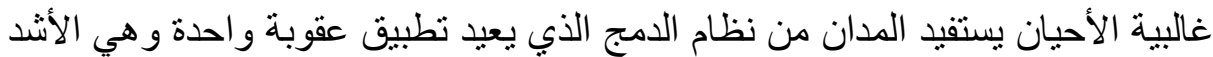
عوضا عن تنفيذ كل عقوبة على حدى. والأشكال يمكن كون إحدى العقوبات المدمجة مستثناة من حق العفو فما هو مصير

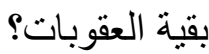
وللاجابة يجب نوضيح نقطة مهمة وهي مسألة الاختصاص بالفصل في مثل هته

\section{1 - 1 مسألة الاختصاص:}

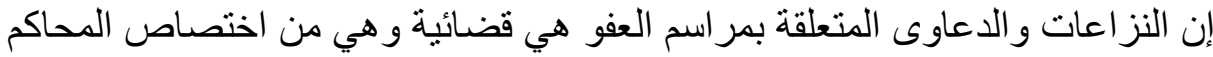

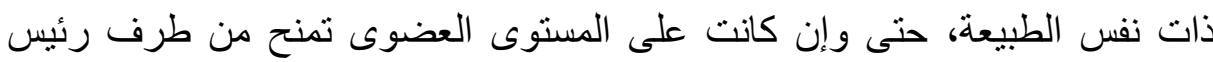
الجمهورية فهي تتعلق بحدود العقوبة وإن تنفيذ هته الأخيرة هو من اختصاص النيابة العامة حسب المادة 10 من القانون 04/05 المتضمن تنظيم السجون كما استقر قضاء المحكمة العليا على أنه في حالة وجود إثكال في تتفيذ هته العقوبة، فإن هذا الإشكال يطرح على أخر جهة قضائية فصلت في الدعوى الدي

كما أن الفقرة الأخيرة من نص المادة 14 من القانون السالف الذكر نصائ فصت على الفى أنه:

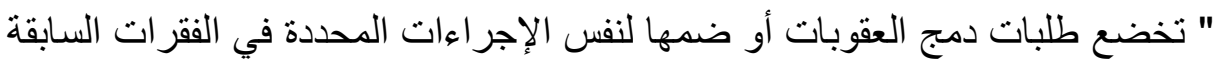

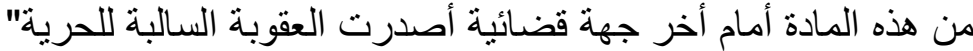

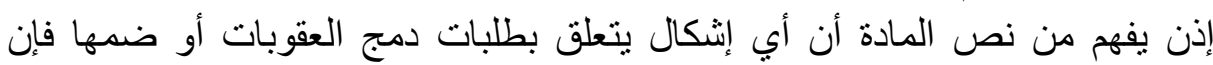

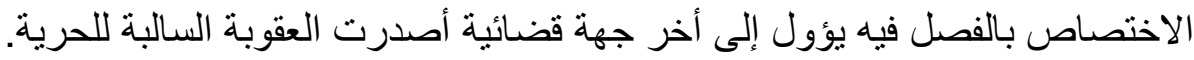
إلا أن مسألة الاختصاص هته قد تجد صعوبات خاصة الفاصة في حالة كون المحكوم عليه

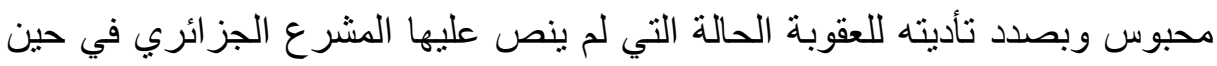

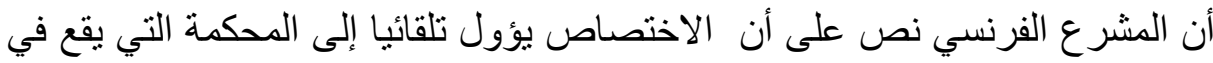

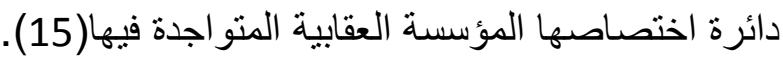

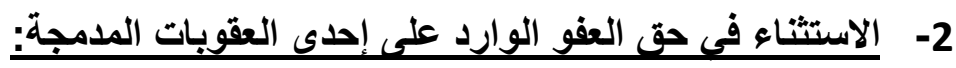

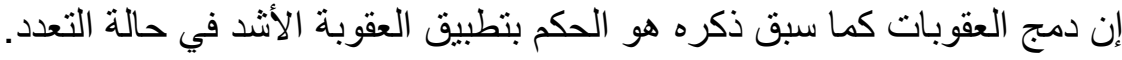

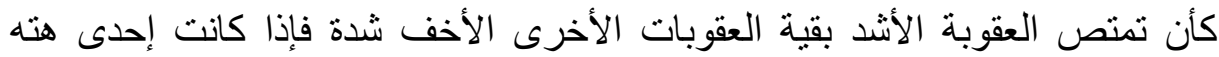

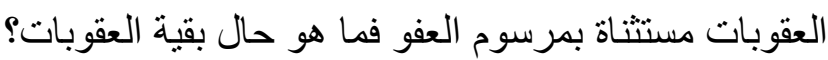

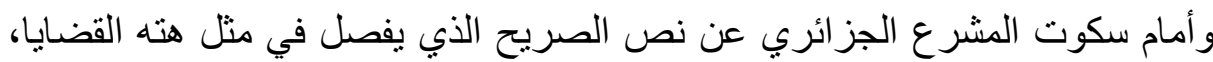

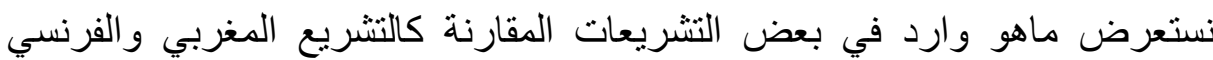
حيث أن المشرع المغربي ينص صراحة واحة على حل هذا الإشكال في الفصل الثالث من 
الظهير الشريف رقم 226-77-1 (16) على أنه " لا يشمل العفو إلا الجريمة أو

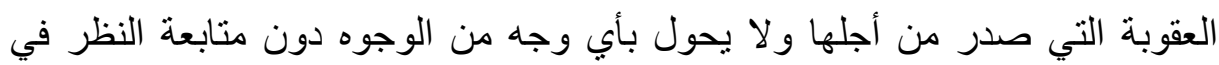

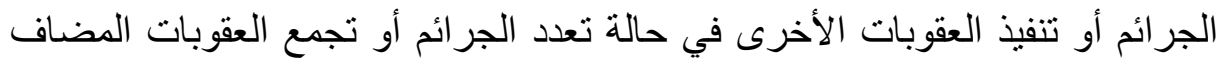

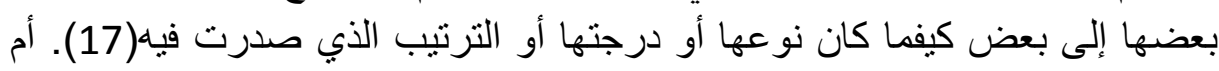

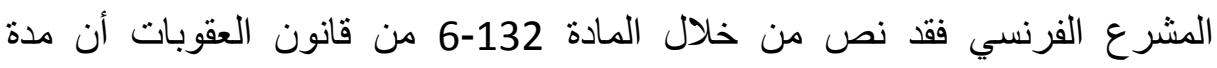

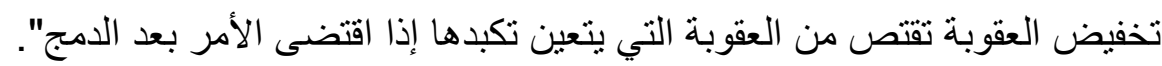

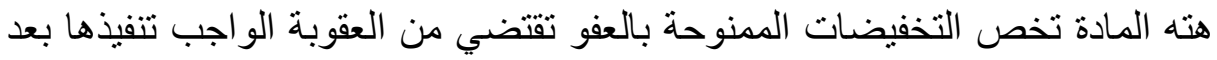

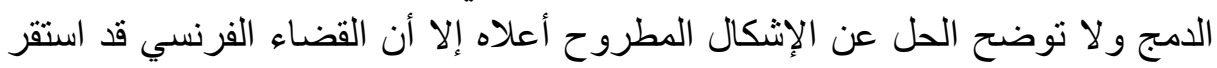

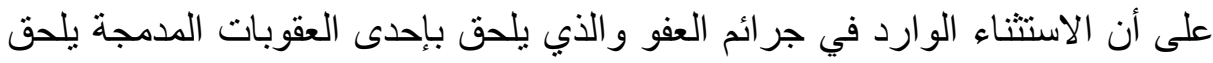
بقية العقوبات الأخرى سواءا كانت العقوبة المستثناة هي العقوبة الممتصة أو أو العقوبة العبة المستو عبة(18).

وفي قرار صادر عن المحكمة الفرنسية أن رفضت المؤسسة العقوبة إعادة محكوم

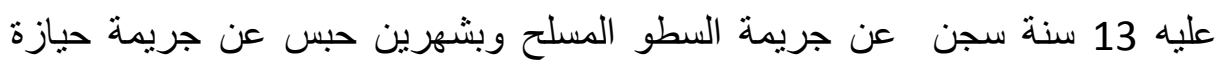

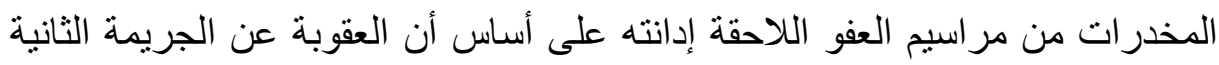
مستثناة من مرسوم العفو. وبعد طعن المحكوم عليه المؤسس على المادة 710 من قانون الإجراءات الجرائم

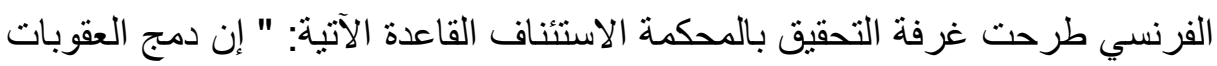

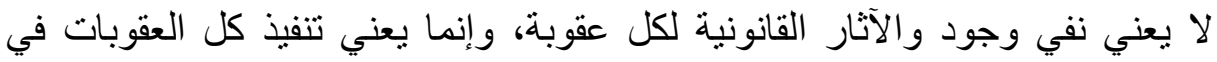

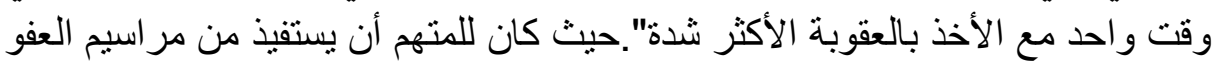

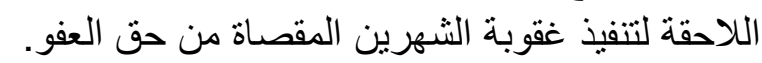

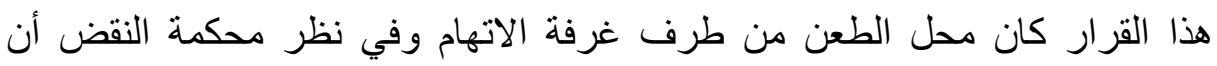

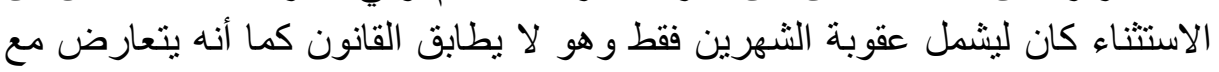

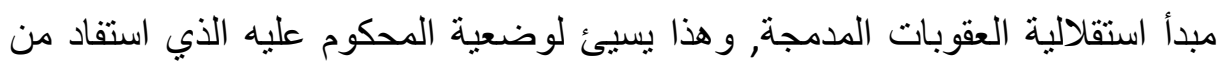

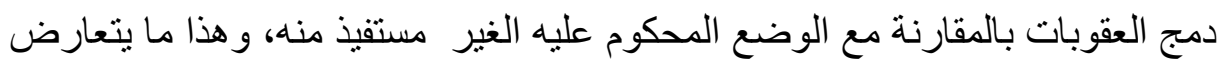

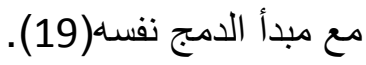
و إستنادا لما سبق فإن الدوريات الخاصة بإدارة القضايا الجنائية والعفو الفرنسية

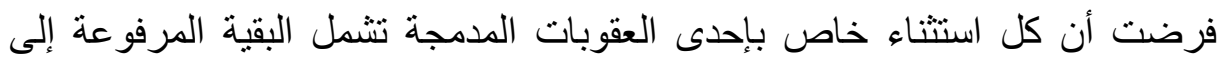

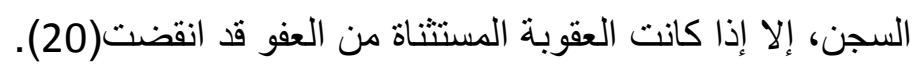
هذا في حالة كون الحكم بدمج العقوبات صادر ا قبل صدور مر اسيم العفو.

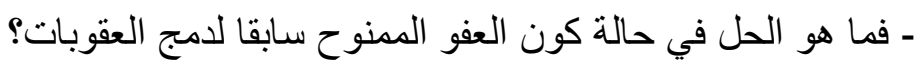

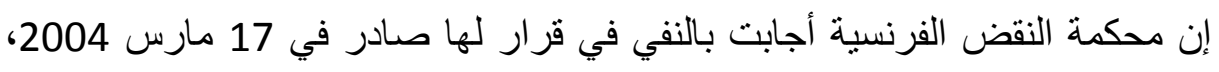

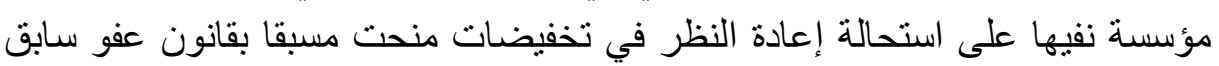

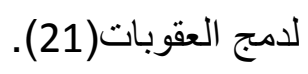




\section{الخاتمة:}

إن دمج العقوبات هو نظام أقره المشرع يستفيذ منه المحكوم عليه بعدة عقوبات مفاده

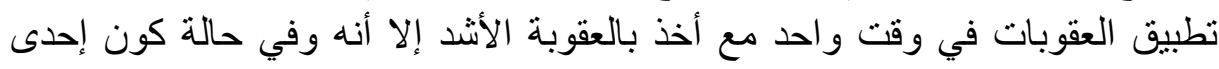

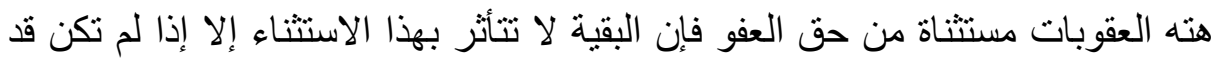

نفذت مسبقا و هذا قد ترتب عليه النتائج التالية:

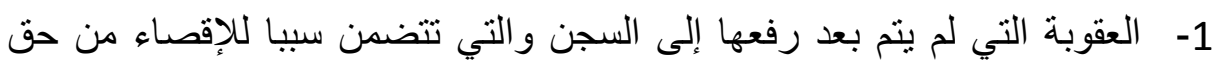

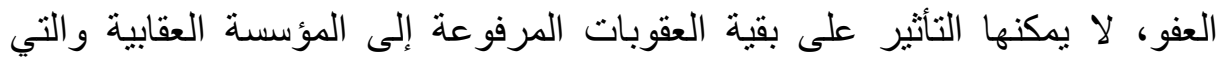

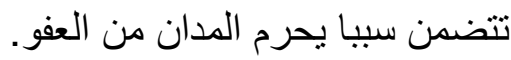

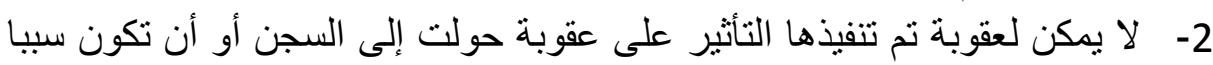
في الحرمان من حق العفو. 3- من ناحية أخرى يحرم المدان من الاستفادة من العفو في حالة تعدد عقوبات لم تنفذ بمجملها وتم تحويلها كلها إلى المؤسسة العقابية.

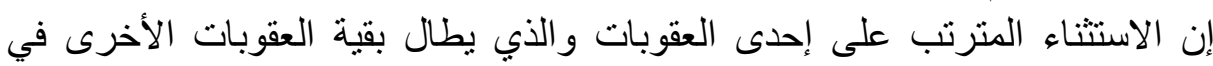

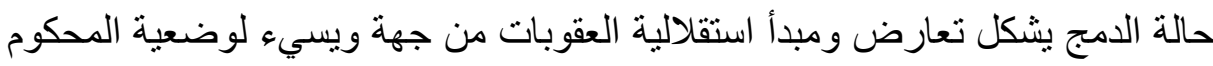
عليه المستفيذ من دمج لعقوباته من جهة لعار أخرى.

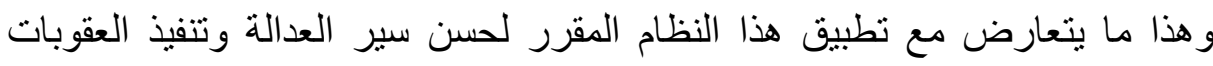

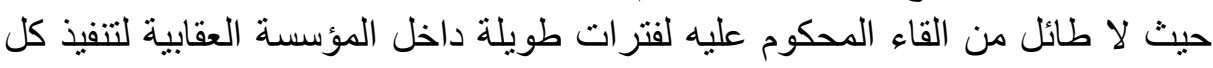
عقوبة على حدى.

ولذلك يكون من الأحسن الحفاظ على تطبيق مبدأ دمج العقوبات الذي يسمح بتسهيل

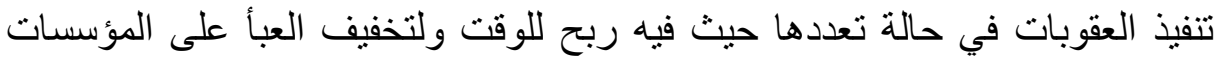
العقابية التي تستقطب عدد كبير من المدانين بعقوبات قد يطول فئ أمر تنفيذها.

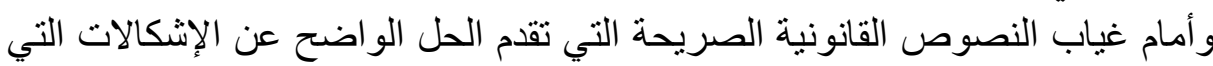

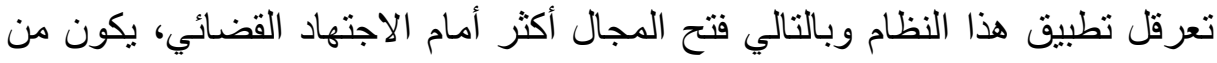

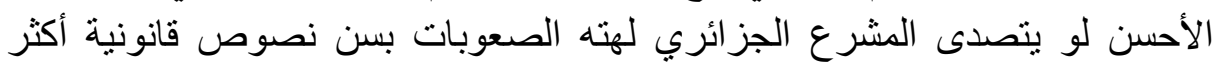

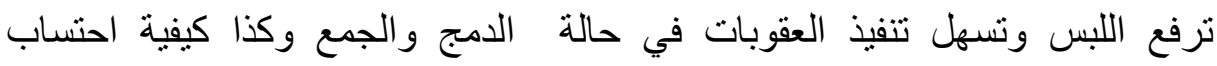
الخصومات الممنوحة بموجب مر اسيم العفو في حالة التعدد. 


$$
\text { الكهوامش: }
$$

1- د. بوراس عبد القادر، العفو عن الجريمة والعقوبة في التشريع الجزائري

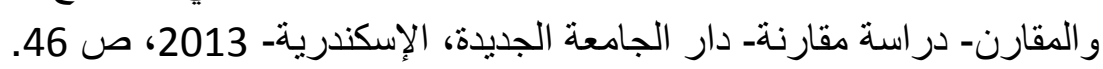

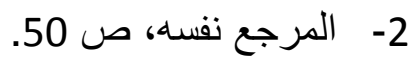

3- مأمون محمد سلامة، قانون العقوبات، دار الفكر العربي، الطبعة الثالثة، القاهرة،

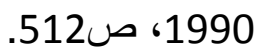

4- المادة 34 من قانون العقوبات الجز ائري.

5- المادة 38 من قانون العقوبات الجزائري.

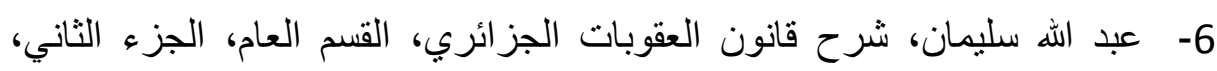

ديوان المطبو عات الجامعية، 2002، ص 7- قرار صادر بتاريخ 1998/12/27، بالمجلة القضائية للمحكمة العليا العدد الأول، وبل،

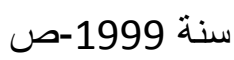

8- أحسن بوسقيعة، الوجيز في القانون الجزائي العام، الديوان الوطني للأشغال التربوية، الجزائر، 2002، ص ص 276. 9- بن نولي زرزور، بوحفارة هدى، ارتباط الجرائم في التشريع الجزائري، مكتبة

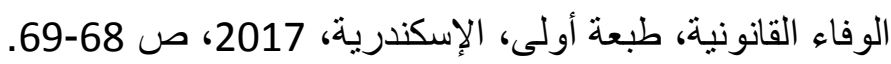

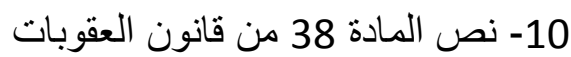
11- نص المادة 37 من قانون العقوبات فئون العقات

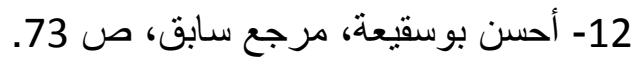

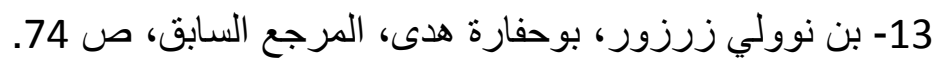

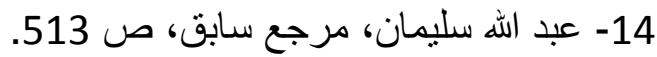

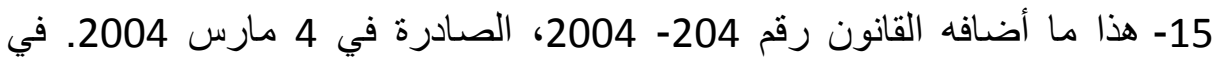
الفقرة الجديدة، لنص المادة 710، من قانون الإجراءات الجزائية الفرنسي.

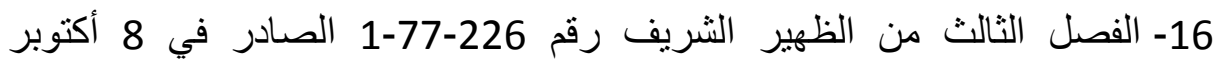
1977، بمثابة قانون بعدل ويتمم بموجبه الظهير الثريف رقم 1387-137-1267 المؤرخ في 8 فيفري 1977، بدنابه 1958، المتعلق بالعفو. 17- د. أحمد محمد بونة، تعدد الجرائم و أثره في العقوبات،في قانون العقوبات الليبي

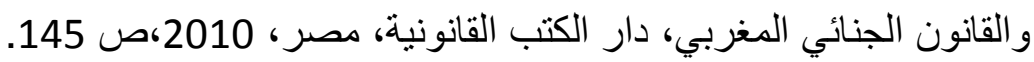
18- Les circulaires de la direction des affaires criminelles des grâces. (Cir.crim 01-13, de 10juillet 2001).

19- Martine herzog.Evans, Complexite du régime des grâces collectives : cumul de peines plurielles Aj pénal, 2005,p 280.

20- (cass crim 20 juin 2001- Bulltin, crim, $\mathrm{n}^{\circ}=155$.

21- Mratine Herzog,Evans, Op,cit, p280. 